
Paper 2008-04

Center for Research in Economic Analysis University of Luxembourg

\title{
Brain Drain, Remittances, and Fertility
}

available online : http://fdef.uni.lu/index.php/fdef_FR/economie/crea/discussion_papers/2008

Luca Marchiori, IRES, Université Catholique de Louvain Patrice Pieretti, University of Luxembourg

Benteng Zou, University of Luxembourg

September 15, 2008 


\title{
Brain Drain, Remittances, and Fertility*
}

\author{
Luca Marchiori ${ }^{\dagger} \quad$ Patrice Pieretti $\ddagger$ Benteng Zou $\S$
}

September 15, 2008

\begin{abstract}
This paper analyzes the effects of skilled migration and remittances on fertility decisions at origin. We develop an overlapping generations model which accounts for endogenous fertility and education. Parents choose the number of children they want to raise and decide upon how many children obtain higher education. Only high skilled individuals migrate with a certain probability and remit to their parents. We find that an increase in the probability to emigrate leads both high and low skilled parents to send more children to obtain higher education. However the effect on the number of children is ambiguous. In a further analysis, we calibrate the model to match different characteristics of a developing economy. When the destination country relaxes the immigration restrictions, more high skilled individuals leave the origin country. The result is that, at origin, increased high skilled emigration reduces fertility and fosters human capital accumulation.
\end{abstract}

Keywords: Skilled emigration, remittances, fertility, human capital.

JEL Classification: F22, F24, J13, J24.

\footnotetext{
${ }^{*}$ We are grateful to Frédéric Docquier for insightful suggestions. This paper also benefited from helpful remarks by Raouf Boucekkine and David de la Croix at the macroeconomic workshop in Louvain-La-Neuve (January 2008). Moreover, we are indebted to two anonymous referees for valuable comments. The first author gratefully acknowledges the financial support from the Government of Luxembourg ("Bourse FormationRecherche, BFR") and from the Belgian French-Speaking Community (ARC grant 03/08-302 "New macroeconomic approaches to the development problem"). Responsibility for the views expressed and any remaining errors is our alone.

${ }^{\dagger}$ IRES, Université catholique de Louvain. E-mail: marchiori@ires.ucl.ac.be.Tel: +32 10473986.

†CREA, Université du Luxembourg. E-mail: patrice.pieretti@uni.lu

§CREA, Université du Luxembourg. E-mail: benteng.zou@uni.lu. Tel:+352 4666446622.
} 


\section{Introduction}

Skilled emigration as well as the flows of migrants' remittances are gaining more and more attention by governments and international organizations, e.g. the report of the World Bank (2006). The reason is that the magnitude of these two phenomena has amplified in recent years. In fact, in the past years high-skilled emigration has risen considerably. According to Docquier and Marfouk (2006), the stock of skilled immigrants in the OECD augmented by 64 percent between 1990 and 2000,, and the increase was stronger for migrants coming from less developed countries (up 93\%), especially from Africa (up 113\%) and Latin America and the Caribbean (up 97\%). Similarly to high-skilled emigration, the amounts of remittances to developing countries have increased enormously since the $70 \mathrm{~s}^{1}$ and are the second largest external financial inflow to developing countries after foreign direct investment and exceeding foreign aid. The Global Economic Prospects (World Bank, 2006) indicate that remittances rose to $\$ 167$ billion $^{2}$ in 2005, up $73 \%$ from 2001 and up 435\% from 1990, pointing out the importance of remittances for developing countries.

Thus, while it can be feared that the brain drain exacerbates North-South inequalities, by depriving developing countries by their most talented workers, it is open to question whether the large amounts of remittances may compensate for the loss of human capital. This paper studies how the brain drain can affect, via remittances, human capital formation, long-term growth and welfare in migrants' origin countries. We develop an overlapping generations (OLG) model with endogenous fertility and education à la de la Croix and Doepke (2003). Parents decide on the quantity (fertility) and quality (education) of their children. In this framework, we assume that only high skilled children migrate with a certain probability and remit to their parents. We study the effects of a more liberal immigration policy (or a more generous exit visa policy), which induces more high skilled children to leave the origin country and parents to expect more remittances.

Our model provides a theoretical analysis of the implications of the brain drain and of remittances on fertility and education decisions at origin. We find that a policy favouring skilled immigration in destination countries or equivalently a higher emigration probability at origin induces both high and low skilled parents to finance higher education to a larger number of their children. However the impact on the number of children is ambiguous. Parents choose to raise more children if the perspective of higher remittances (sent back by their emigrated children) dominates the increased

\footnotetext{
${ }^{1}$ The size of remittances is not increasing in each developing country, e.g. in Morocco and Turkey remittances have become a less important source of revenue (see Rapoport and Docquier, 2007 and the World Bank, 2006).

${ }^{2}$ These numbers are considered to be under-estimated as they do not include remittances via informal channels (through informal operators or hand carried by travellers) as they are unlikely to be captured in official statistics.
} 
education expenditures they have to face by sending more children to obtain higher education.

To provide some quantitative answers, we calibrate our model for a developing country, the Philippines. We introduce a production side of the economy by considering two sectors that produce the same final good as in Galor and Zeira (1993). One sector only employs low skilled labor with no capital, and another one uses high skilled labor and capital. Our findings are that a $1 \%$ increase in the probability to emigrate leads to a long term reduction of $3.87 \%$ in the population growth rate, while the share of high to low skilled population will be enhanced by $3.39 \%$.

The paper is organized as follows. In section 2 we relate our paper to the literature. Section 3 presents the model and explains the theoretical effects of a more liberal immigration policy. In section 4, numerical exercises depict the effects of a laxer immigration policy on the Philippine economy. Section 5 concludes.

\section{The contribution to the literature}

Our paper is related to two strands of the migration literature. First, it investigates the consequences of the brain drain on the source country's economy. Economic researchers devoted much attention to the study of the consequences of high skilled emigration (brain drain) on the countries of origin. The early economic literature of the 1960s (e.g. Grubel and Scott 1966) pointed out that the impact of the brain drain on origin countries is rather neutral and that any negative consequence for the remaining population is only negligible. During the 1970s, economists held a different and more pessimistic view on the brain drain issue, stressing the effects of negative externality of skilled emigration on sending countries (e.g. Bhagwati and Hamada, 1974).

The recent literature is more optimistic. ${ }^{3}$ The new line of studies highlights diverse positive side-effects of high skilled emigration on origin countries. Skilled emigration can for example foster human capital formation at origin that leads to a production of human capital in the origin country outweighing the human capital loss due to emigration (Mountford, 1997, Stark et al. 1997, Beine, Docquier and Rapoport, 2001, and Stark and Wang, 2002). ${ }^{4}$ Most of the migration models consider that population is constant and do not take into account fertility and decisions faced by parents. In

\footnotetext{
${ }^{3}$ One exception is Haque and Kim (1995).

${ }^{4}$ Docquier (2006) provides an extensive overview of the beneficial side-effects of skilled emigration. One of these channels are networks or diaspora, which are essential means for trade, investment and technology transfer from North America and Europe to the less developed countries (Rauch, 2003). Skilled migration may stimulate aggregate FDI inflows in the origin country. Moreover, return migration can also be beneficial to the origin country via the additional skills acquired abroad by return migrants (Dos Santos and Postel-Vinay, 2003). Another important channel concerns remittances sent back by emigrants to their country of origin.
} 
fact, Becker and Barro (1988) demonstrated the importance of the quality-quantity trade-off faced by parents for a country's economic growth. de la Croix and Doepke (2003) also showed that this trade-off affects inequality. As the quality-quantity trade-off is important for a country's economic growth as it determines the country's human capital accumulation, it seems straightforward to apply a model of endogenous fertility to the brain drain issue. While our model yields similar results in terms of human capital accumulation as e.g. Moundfort (1997), Stark et al. (1997), it differs from these models in such that it also provides results in terms of fertility behavior. Clearly all the "brain gain" studies lack in giving insights to the fertility choices of agents, which has however been stressed to be an important factor in explaining economic development. To our knowledge, the only study developing an OLG model with endogenous fertility to deal with the impacts of the skilled emigration on the source country education level is Chen (2006). Among other differences with our model, the stochastic partial equilibrium model used by Chen does not incorporate remittances. We propose a model in which skilled emigration and the prospect of remittances contribute to shape the household's fertility and education choices and thus human capital formation at origin.

Our paper is also linked to the 'remittances and growth' literature. In fact, remittances are another channel that can mitigate the negative effects of the brain drain. However, "the impact of remittances on home country growth is open to question" (Faini, 2007). In their surveys about the effects of remittances, Taylor (1999) and Rapoport and Docquier (2005) report studies analyzing how remittances are employed by the recipient. These "remittances-use studies" often conclude that remittances are used in consumption and not invested productively (see Böhning 1975, Rempel and Lobdell 1978 and the recent IMF study of Chami, Fullenkamp and Jahjah 2005). ${ }^{5}$ However there is a lot of criticism on the negative view of these studies ${ }^{6}$ because they do not take into account indirect effects of remittances on incomes of the migrant's family members remaining in the source country. Remittances may for example ease liquidity constraints or finance education. But most "remittances-use studies" do not consider education as a productive investment (Taylor, 1999:p72). The impact of remittances has traditionally been analysed in trade models with traded and non-traded goods, either in a partial equilibrium, see for example Lucas and Stark (1985), or in a general equilibrium framework, see for

\footnotetext{
${ }^{5}$ More precisely, Chami, Fullenkamp and Jahjah, (2005) claim that a large proportion of remittances are used for consumption, especially to finance education costs, used in a non-productive way, while only a small part enters in the capital accumulation process. Another view is that the remitter is often separated by long distances from the recipient of the transfer, not directly able to observe the use of the remittances. Remittances are thus exposed to asymmetric information. Higher remittances may therefore worsen agency and moral hazard problems reducing. Economic activity may decline because the recipient reduces his work effort and labor force participation, limits his job search and invests in risky projects (Chami, Fullenkamp and Jahjah, 2003).

${ }^{6}$ See for example Adams (2005) who provides an opposite view to Chami, Fullenkamp and Jahjah (2005) in a case study on Guatemala.
} 
example Lundahl (1985). ${ }^{7}$ However, the literature does not provide, to our knowledge, an analysis of the effects of remittances in a dynamic general equilibrium OLG model with endogenous fertility.

\section{The Economic Model}

We develop an overlapping generations model of the migrants' source country. Households take fertility and education decisions along the lines of Becker and Barro (1988) and de la Croix and Doepke (2003). When fertility and education are chosen endogenously, parents face a trade-off between the quality and quantity of their children.

In this economy individuals live for 3 periods (childhood, adulthood, and old age). Each individual has one parent, which creates the connection between generations. People work only when they are adults and earn a wage depending on their education level, that they acquire when they are children. Individuals are characterized either by a low (superscript $l$ ) or by a high education level (superscript $h$ ). The society offers free low education while high education is costly ${ }^{8}$. Individuals who benefited from higher education during their childhood will have a high skilled job when adult and earn a wage $w^{h}$, while individuals with a low education level will have a low skilled job and earn a wage $w^{l}$ where $w_{t}^{h}>w_{t}^{l}$, for any $t \geq 0$.

We assume that there is international labor mobility and except remittances from emigrants, there is no international capital mobility in this economy. We justify this assumption by pushing to its extreme the fact, identified as the Lucas' paradox, that capital is not perfectly mobile (Lucas, 1990). We consider that only high skilled individuals migrate. ${ }^{9}$ Moreover, we assume that migration is not

\footnotetext{
${ }^{7}$ Trade models on remittances and migration feature endogenous migration and remittances in partial equilibrium frameworks and exogenous migration and remittances in general equilibrium frameworks. McCormick and Wahba (2000) combined these two literatures by developing a general equilibrium trade model with endogenous migration and remittances.

${ }^{8}$ For example, we could think of individuals with a college degree as high skilled and individuals without a college degree as low skilled. In this case education below college would be free while education in college is costly.

${ }^{9}$ Obviously, low skilled migration is not a negligible phenomenon and contributes to a large proportion to the remittances recorded by the World Bank. In general, unskilled migration is mainly studied for its impact on the destination countries, since it might for example negatively affect the labor market outcomes of destination/developed countries (see e.g. Card, 1990). On the contrary, the literature analysis skilled migration when it pays attention to developing countries since a brain drain might deprive the source country from its most talented labor force. Thus in this present framework, since we are interested in developing economies we will focus on the consequences of skilled emigration. Our relatively strong assumption that only skilled migrants remit to their parents might however not necessarily exclude transfers from non-migrating individuals to their
} 
so large to affect the economy of the destination country. In fact, the evidence on the consequences of immigration on labor market outcomes in host countries is not clear-cut. Empirical studies hint at the fact that the impact of immigration on wages at destination is small or even nil (see e.g. Card, 1990 or the survey of Friedberg and Hunt, 1995).

\subsection{Individual behavior}

All decisions are made by the individual during her adulthood. Thus at time $t$, each adult of education level $i$ decides about her own consumption $c_{t}^{i}$, her old age consumption $d_{t+1}^{i}$ (through savings $s_{t}^{i}$ ), and the number of children $\left(n_{t}^{i}\right)$ she would like to have, of which $m_{t}^{i}\left(\leq n_{t}\right)$ will get high education (with $i=l, h)$. And finally, the individual also cares about the return from her "education investment", that is, the expected income of her kids $E_{t}^{i}$.

Suppose that low educated children can only work in the home country while high educated children can emigrate to a more advanced economy, with a probability $p$, where they can earn a higher wage $w^{*}>w^{h}$, which is exogenous. Hence the expected income of an adult's kid is the sum of incomes of her low educated and of her high educated children:

$$
E_{t+1}^{i}=\left(n_{t}^{i}-m_{t}^{i}\right) w_{t+1}^{l}+m_{t}^{i} \bar{w}_{t+1} .
$$

where $\bar{w}=(1-p) w_{t+1}^{h}+p w^{*}$. The utility function of an individual who is an adult at time $t$ is then given by:

$$
U_{t}^{i}=\ln \left(c_{t}^{i}\right)+\beta \ln \left(d_{t+1}^{i}\right)+\gamma \ln \left(E_{t+1}^{i}\right), \quad i=l, h,
$$

where $\beta(>0)$ is the preference factor for the future, $\gamma(>0)$ is the altruism factor, and $E_{t}^{i}$ is the expected income of children born at time $t$.

Raising one child takes time fraction $\phi \in(0,1)$ of an adult's time, and the parents care both about the number of their children and their education (or quantity and quality of the children). High education is costly and the government charges an amount $x$ for each high educated child. An adult's budget constraint writes then as follows:

$$
c_{t}^{i}+s_{t}^{i}+m_{t}^{i} x=w_{t}^{i}\left(1-\phi n_{t}^{i}\right), \quad i=l, h,
$$

We assume that $x<w_{t}^{h}$, which is one of the sufficient conditions to have an interior solution. Otherwise, education would be too costly, and an adult would optimally choose to have no high educated parents. In fact, we could imagine that there is an implicit transfer from non-migrating individuals (thus also from low skilled) to parents in the form of old age care. Then in our model, remittances might simply represent the additional transfers from high skilled emigrating individuals compared to an average (implicit) level of old age care to parents. Put differently, and to make it simple, we assume that the remittances are received by the parents as a refunding to their investment of children's education. 
child. This condition implies that the cost of education is exogenous and does not depend on the parent's wage. Education is therefore relatively more expensive for unskilled parents.

The consumption of an old age individual is financed by savings and by potential remittances from her children. The budget constraint of the old aged is:

$$
d_{t+1}^{i}=R_{t+1} s_{t}^{i}+M_{t+1}^{i}, \quad i=l, h
$$

where $R_{t+1}$ is the interest factor, and $M^{i}$ is expected remittances. We assume that only emigrated kids will remit to their parents ${ }^{10}$ up to a fixed percentage $\theta$ of their extra foreign wage. Then expected remittances equal

$$
M_{t+1}^{i}=\left(m_{t}^{i}\right)^{\mu}\left[p \theta\left(w^{*}-w_{t+1}^{h}\right)+(1-p) 0\right]=p \theta\left(m_{t}^{i}\right)^{\mu}\left(w^{*}-w_{t+1}^{h}\right) .
$$

Here we assume that remittances are an increasing concave function with respect to the number of high educated children, therefore parameter $0<\mu<1$. Thus there are decreasing returns to scale, because an increase in the number of children working in an advanced economy will raise the total amount of remittances, but reduce the amount of remittances per emigrated child. ${ }^{11}$

\subsection{Solving the model}

After substituting (1), (3), (4) and (5) into (2), the optimization problem results in the maximization of the utility functions with respect to $s_{t}^{i}, n_{t}^{i}$ and $m_{t}^{i}$ for $i=h, l$.

More precisely, the first order condition of the household's problem with respect to $s_{t}^{i}$ shows the following standard consumption relationship between young and old age:

$$
d_{t+1}^{i}=\beta R_{t+1} c_{t}^{i}
$$

Similarly, the first order condition of the household's problem with respect to the number of kids leads to

$$
\gamma \frac{w_{t+1}^{l}}{E_{t+1}^{i}}=\frac{\phi w_{t}^{i}}{c_{t}^{i}}
$$

which reads that the marginal cost of raising one child, $\phi w_{t}^{i}$, in terms of consumption, should equal the marginal low skilled labor income, after "discounting" by the altruism factor. If this inequality

\footnotetext{
${ }^{10}$ See footnote 10 for further interpretation.

${ }^{11}$ This assumption is consistent when the motivation to remit rests on altruism. By taking a simple altruism utility function à la Lucas and Stark (1985), it can easily be proven that remittances per migrant are decreasing with the number of family members abroad. A similar idea is also presented by de la Croix and Dottori (2008). Since we are focus on brain-drain and remittance effect, to make it simple, we take the simplest form in (5), and we do not exclude the case where if there is no remittance there is still high education.
} 
does not hold, raising children is either too costly (then it is optimal to have no children), or not costly enough (then having more children increases future income $E$ ).

The first order condition of the household's problem with respect to the number of kids who obtained high education $m_{t}^{i}$ gives

$$
\frac{x}{c_{t}^{i}}=\beta \frac{\mu}{m_{t}^{i}} \frac{M_{t+1}^{i}}{d_{t+1}^{i}}+\gamma \frac{\bar{w}_{t+1}-w_{t+1}^{l}}{E_{t+1}^{i}},
$$

which presents that the marginal cost of educating one kid $x$ in terms of consumption (left hand side), should be equal to the marginal benefit from educating a child, which comprises remittances (first term) and the wage differential (second term). The second order conditions of the agents' maximization problem are satisfied.

Plugging (3) and (4) into (6) yields the savings equation:

$$
s_{t}^{i}=\frac{\beta}{1+\beta}\left[w_{t}^{i}\left(1-\phi n_{t}^{i}\right)-m_{t}^{i} x\right]-\frac{1}{1+\beta} \frac{M_{t+1}^{i}}{R_{t+1}} .
$$

Similarly, after replacing (1) and (3) into (7), we obtain the optimal number of children chosen by the households:

$$
n_{t}^{i}=\frac{\gamma}{1+\gamma} \frac{1}{\phi w_{t}^{i}}\left[w_{t}^{i}-s_{t}^{i}-m_{t}^{i} x\right]-\frac{1}{1+\gamma} m_{t}^{i}\left(\frac{\bar{w}_{t+1}}{w_{t+1}^{l}}-1\right) .
$$

Finally, after substituting (6) and (7) into (8) and rearranging, we get

$$
\frac{\mu}{m_{t}^{i}} \frac{M_{t+1}^{i}}{R_{t+1}}+\phi w_{t}^{i}\left(\frac{\bar{w}_{t+1}}{w_{t+1}^{l}}-1\right)=x,
$$

which implicitly requires that the relationship between education cost and wages should check the following condition

$$
x>\phi w_{t}^{i}\left(\frac{\bar{w}_{t+1}}{w_{t+1}^{l}}-1\right) .
$$

The first term on the left hand side in equation (11) is the parents' marginal gain from obtained remittances from one educated child $(M / m)$, while the second term is the marginal gain from having a child that earns a relative higher wage $\left(\bar{w} / w^{l}\right)$. These two elements represent the gain of educating one child. Therefore equation (11) states that the marginal gain of educating one child should be equal to the marginal cost of eduction per kid (right hand side of (11)). Using the specification of our remittances function (5) in condition (11), we can obtain an explicit form for the optimal number of educated children chosen by the households,

$$
m_{t}^{i}=\left\{\frac{1}{R_{t+1}} \frac{\mu p \theta\left(w^{*}-w_{t+1}^{h}\right)}{x-\phi w_{t}^{i} \Delta_{t+1}}\right\}^{\frac{1}{1-\mu}} .
$$

where $\Delta_{t+1}$ stands for the (expected) relative wage difference $\Delta_{t+1} \equiv \frac{\bar{w}_{t+1}}{w_{t+1}^{l}}-1$. 


\subsection{Comparative statics}

In the following analysis we investigate how the number of children obtaining high education, savings and the number of children vary when the probability of emigrating changes. The chance to emigrate often depends on the immigration laws in the destination country. A rise in $p$ can thus be associated to a more liberal migration policy or to a more generous exit visa policy. This could amount in a reduction of the barriers at entry in the destination country, or by higher exit quotas in the origin country. ${ }^{12}$

After taking the derivative ${ }^{13}$ of equation (11) with respect to $p$ and rearranging, we notice that

$$
\frac{\partial m_{t}^{i}}{\partial p}=\frac{1}{1-\mu} m_{t}^{i} R_{t+1}\left[\frac{x-\phi w_{t}^{i} \xi_{t+1}}{p\left(x-\phi w_{t}^{i} \Delta_{t+1}\right)}\right]>0,
$$

with $\xi_{t+1}=\frac{(1+p) w_{t+1}^{h}}{w_{t+1}^{l}}-1$.

From (14) we see that a rise in the chance for high educated kids to emigrate to an advanced economy leads to more remittances for parents when old and augments the number of kids who obtain higher education. In other words, a higher emigration probability leads to more incentives for higher education.

On the other hand, from (7) and (8), it is easy to see that if $p \rightarrow 0$, there is no chance to go abroad or the chance is very low, then there is no chance to refund parents when they are old (see equation 5), and parents lose their incentive to give high education to their kids. Therefore, they will base on the education cost $x$, on the cost of raising one child $\phi w_{t}^{i}$ and on the future wage difference their kids will face $w_{t+1}^{h}-w_{t+1}^{l}$ to decide which of the two corner solutions (either no kid gets high education, or all kids get high education) to take.

The saving function can also be rewritten as ${ }^{14}$

$$
s_{t}^{i}=\frac{1}{1+\beta+\gamma}\left[\beta\left(w_{t}^{i}-m_{t}^{i} x+\phi w_{t}^{i} m_{t}^{i} \Delta_{t+1}\right)-(1+\gamma) \frac{M_{t+1}^{i}}{R_{t+1}}\right],
$$

or in the following form, which allows us to see more clearly the effect of $p$ on savings

$$
s_{t}^{i}=\frac{1}{1+\beta+\gamma}\left[\beta w_{t}^{i}-(1+\gamma+\beta \mu) \frac{M_{t+1}^{i}}{R_{t+1}}\right] .
$$

Hence an increase in the probability to emigrate leads to

$$
\frac{\partial s_{t}^{i}}{\partial p}=-\frac{1+\gamma+\beta \mu}{1+\beta+\gamma} \frac{M_{t+1}^{i}}{R_{t+1}}\left[\frac{1}{p}+\frac{\mu}{m_{t}^{i}} \frac{\partial m_{t}^{i}}{\partial p}\right]<0,
$$

\footnotetext{
${ }^{12}$ For an interesting theoretical work comparing the different implications o migration policies at origin and at destination see Casarico et al. (2008).

${ }^{13}$ Since in this section we only study how the optimal choices of the households are affected by $p$, interest rate and wages need not to be derived with respect to $p$.

${ }^{14}$ See appendix A.1 for analytical details on how to obtain this equation.
} 
which states that when the chance to emigrate increases, more children get higher education, which is costly. To finance more higher education, parents will reduce their savings, which they need for their future consumption. Nevertheless, higher educated children will refund their parents' loss through more remittances (see equation 15).

Similarly, the trade-off between total number of children and high educated children follows

$$
\phi \beta w_{t}^{i} n_{t}^{i}+\beta x m_{t}^{i}=\frac{\gamma \beta w_{t}^{i}}{1+\beta+\gamma}+\frac{(\gamma+\mu+\mu \beta) M_{t+1}^{i}}{(1+\beta+\gamma) R_{t+1}},
$$

which says that the total cost of raising $n^{i}$ kids and of financing high education to $m^{i}$ kids will be the same as the total gain from children, which includes discounted wage now and excepted remittances from kids.

A change in $p$ yields

$$
\phi \beta w_{t}^{i} \frac{\partial n_{t}^{i}}{\partial p}=\frac{(\gamma+\mu+\beta \mu)}{(1+\beta+\gamma)} \frac{M_{t+1}^{i}}{R_{t+1}}\left[\frac{1}{p}+\frac{\mu}{m_{t}^{i}} \frac{\partial m_{t}^{i}}{\partial p}\right]-\beta x \frac{\partial m_{t}^{i}}{\partial p},
$$

where the coefficients of the first term is positive and the last term is negative. The probability to emigrate has an ambiguous effect on the number of children. Two effects are at play in equation (19). First, the direct effect of an increase in the probability to emigrate will lead to more remittances, which will directly raise the number of kids (first term in 19). However, the indirect effect of $p$ on $n$ will be that a higher chance to emigrate requires higher education and thus more expenditures in education (the last term), which reduces the number of kids.

We conclude the above analysis in the following proposition:

Proposition 1. Suppose that the condition on the education cost checks (12). Then increasing the chance to emigrate to an advanced economy will increase the number of high educated children, reduce the savings for the old age, while having an ambiguous effect on the number of children.

\subsection{Output sector}

Our production side of the economy is similar to Galor and Zeira (1993) and is characterised by two sectors that produce the same final good. One sector only employs low skilled labor with no capital and another one uses high skilled labor and capital. Production in the high skilled labor sector $Y^{h}$ is described by $Y^{h}=F\left(K, L^{h}\right)$ where $K$ is physical capital. Furthermore, we assume that the output function is an increasing function, with constant returns to scale, and that it checks Inada's conditions. In the following analysis we will take, for simplicity, a Cobb-Douglas output function

$$
Y^{h}=F\left(K, L^{h}\right)=K^{\alpha}\left(L^{h}\right)^{1-\alpha}=f\left(k_{t}\right) L^{h},
$$


where per skilled-labor capital $k=\frac{K}{L^{h}}, f(k)=k^{\alpha}, \alpha$ is the share of capital in output $(0<\alpha<1)$ and $A$ is (time-constant) total factor productivity.

The representative firm chooses inputs by maximizing profits $\Pi$

$$
\Pi_{t}=Y_{t}^{h}-w_{t}^{h} L_{t}^{h}-R_{t} K_{t} .
$$

Simple calculations give capital rent

$$
R_{t}=\alpha K_{t}^{\alpha-1}\left(L_{t}^{h}\right)^{1-\alpha}=\alpha A k_{t}^{\alpha-1},
$$

and the wage of high skilled workers

$$
w_{t}^{h}=(1-\alpha) A k_{t}^{\alpha} .
$$

Production in the low skilled sector is given by

$$
Y_{t}^{l}=w_{t}^{l} L_{t}^{l}
$$

where $Y_{t}^{l}$ is the output of low skilled labor, and $w_{t}^{l}$ is given exogenously:

$$
w_{t}^{l}=\frac{1}{\epsilon} w_{t}^{h}
$$

where $\epsilon$ is a fixed skill premium.

Furthermore the wage-rental ratio writes as follows

$$
\frac{w_{t}^{h}}{R_{t}}=\frac{1-\alpha}{\alpha} k_{t}
$$

The market-clearing conditions of both types of labor are given by

$$
\begin{aligned}
L_{t}^{h} & =\left(1-\phi n_{t}^{h}\right) N_{t}^{h}, \\
L_{t}^{l} & =\left(1-\phi n_{t}^{l}\right) N_{t}^{l},
\end{aligned}
$$

where $N_{t}^{i}$ is the size of adult population of skill type $i$ at time $t$ (and staying in the home country). The evolution of the low- and high-skilled generations are then given by

$$
\begin{gathered}
N_{t+1}^{h}=(1-p)\left(N_{t}^{h} m_{t}^{h}+N_{t}^{l} m_{t}^{l}\right), \\
N_{t+1}^{l}=N_{t}^{h}\left(n_{t}^{h}-m_{t}^{h}\right)+N_{t}^{l}\left(n_{t}^{l}-m_{t}^{l}\right) .
\end{gathered}
$$

The market-clearing condition for capital is:

$$
K_{t+1}=(1-\delta) K_{t}+\left(N_{t}^{h} s_{t}^{h}+N_{t}^{l} s_{t}^{l}\right)
$$


where $\delta \in[0,1]$ is the depreciation rate of capital and the second term represents the savings of total active workers. In the following, for the sake of simplicity, we will take $\delta=1$.

The optimal conditions of the household's problem give us 6 equations and 6 unknowns $\left(s_{t}^{i}, n_{t}^{i}\right.$, $m_{t}^{i}$ with $\left.i=h, l\right)$ in terms of $R_{t}, w_{t}^{h}$ and $w_{t}^{l}$. By using the optimal conditions of the firm's profit maximization problem (see equations 22, 23, and 24) these 6 unknowns and 6 equations can be written in terms of $K_{t}, L_{t}^{h}$, and $L_{t}^{l}$. Hence the market clearing conditions (equations 28, 29, and 30) leave us with a system of 3 dynamic equations for 3 unknowns.

\section{Numerical Analysis}

In this section, we study the behavior of our economy if a more liberal immigration policy is adopted at destination. In fact, an increase in the probability to emigrate $p$ can be interpreted as a change in the immigration policy of the destination country. From the previous section, we know that a lax immigration policy induces parents to invest in the "quality" of their children. A natural issue to raise is whether these higher investments in human capital can compensate the loss of skilled individuals. Thus, we will concentrate on the effects of increased skilled emigration on fertlity and education levels. We will also quickly look at the consequences on the economic performance, on inequality (coming from wage differences), and on the welfare of the remaining population in the sending country.

Before turning to the numerical results, we introduce the different economic indicators we are looking at and present the calibration of the different parameters used in the model.

\subsection{Economic indicators}

In our analysis, we focus in particular upon the effects of a more liberal immigration policy at destination on fertility and human capital at origin. We also look at changes per capita GDP, per capita welfare and inequality, measured as high-to-low skilled welfare. Let us define some of these indicators.

Human capital is measured as the share of high to low skilled population,

$$
H_{t}=\frac{N_{t}^{h}+N_{t-1}^{h}}{N_{t}^{l}+N_{t-1}^{l}}
$$

and per capita GDP writes as follows

$$
y_{t}=\frac{Y_{t}^{h}+Y_{t}^{l}}{N_{t}^{h}+N_{t-1}^{h}+N_{t}^{l}+N_{t-1}^{l}}
$$


We define total social welfare in terms of utility from consumption of both adult and old individuals. Then, per capita welfare $\Omega$ corresponds to

$$
\Omega_{t}=\frac{N_{t}^{l} \ln c_{t}^{l}+N_{t}^{h} \ln c_{t}^{h}+N_{t-1}^{l} \ln d_{t}^{l}+N_{t-1}^{h} \ln d_{t}^{h}}{N_{t}^{l}+N_{t}^{h}+N_{t-1}^{l}+N_{t-1}^{h}} .
$$

A broad measure of inequality corresponds to the ratio of welfare of a skilled individual to the welfare of a low skilled individual:

$$
\Psi_{t}=\frac{\Omega_{t}^{h}}{\Omega_{t}^{l}}
$$

where the welfare of an individual of education $i, \Omega_{t}^{i}$, is the sum of welfare of young and old individuals of type $i$ divided by population of type $i$ at date $t$.

$$
\Omega_{t}^{i}=\frac{N_{t}^{i} \ln c_{t}^{i}+N_{t-1}^{i} \ln d_{t}^{i}}{N_{t}^{i}+N_{t-1}^{i}}
$$

\subsection{Calibration}

Table 1 summarizes the values that are chosen for the different parameters of our economy in the baseline scenario. Known exogenous variables are the following. The raising cost parameter $\phi$ equals 0.15, since Haveman and Wolfe (1995) demonstrated that parents spend around $15 \%$ of their time raising children. To calibrate the remaining parameter values we choose as Chen (2006) the USA as the foreign country and the Philippines as the source country. The choice of the Philippines is justified since "international migration and large remittance flows have been prominent features of the Philippine economy for many decades" (Burgess and Haksar, 2005). We calibrate the initial steady state basing on 2000 data. According to Rosenzweig (2006), the wage of a skilled worker in the Philippines is 5.02 times larger than the one of unskilled, thus the skill premium $\epsilon$ equals 5.02.

Table 1: Parameter values for the Philippines

\begin{tabular}{ccccc}
\hline$\beta=0.8$ & $\phi=0.15$ & $\alpha=0.333$ & $\mu=0.5$ & $\epsilon=5.02$ \\
$\gamma=1.33$ & $\theta=0.481$ & $w^{*}=0.99$ & $x_{t}^{l}=0.04$ & $x^{h}=0.19$ \\
\hline
\end{tabular}

The model contains some exogenous variables for which data are not available. Since one period in our model is considered to be 20 years, we set the discount factor, $\beta$ to 0.8 which points at an annual discount rate of $1.1 \%$. The share of capital revenues to high skilled production, $\alpha$, is chosen to be 0.333 and the parameter in the remittances function $\mu$ is set to 0.5 . In section 4.4 , we provide some robustness analysis with respect to these parameters. 
Values for six other parameters remain to be set. These exogenous variables are used in order to satisfy various characteristics of the economy in the Philippines. ${ }^{15}$ Basically, our identification process consists in swapping the four exogenous variables for four endogenous variables. These four exogenous variables are: the share of additional income remitted $\theta$, the altruistic parameter $\gamma$, the foreign wage $w^{*}$ and the education cost of a child belonging to a skilled individual $x^{h}$ (after having given a value to $\left.x^{l}\right) .{ }^{16}$ The calibrated values for these parameters check the following characteristics of the Philippines: (i) the average wage differential between the USA and the Philippines, $\omega$, (ii) the population growth rate, $g$, (iii) remittances sent back by skilled migrants as a share of GDP, $\Gamma$, and (iv) the ratio of unskilled-to-skilled in one generation, $\Theta$. The last exogenous variable to set is $p$. It is chosen as to satisfy these various characteristics of the Philippine economy.

Let us now describe the construction of the four endogenous variables we want to meet at the steady state. According to the World Development Indicators (WDI 2006), average per capita GDP between 1995-2004 was \$3,946 in the Philippines and \$33,316 in the USA, thus 8.44 times higher in the USA. We consider the wage differential between these two countries to be similar to the per capita GDP differential. Thus in our simulations, the foreign wage $w^{*}$ is set to 0.990371 to have that $\omega=w^{*} / \hat{w}=8.44$, where $\hat{w}$ is the average wage in the domestic economy: $\hat{w}=\left(N^{h} w^{h}+\right.$ $\left.N^{l} w^{l}\right) /\left(N^{h}+N^{l}\right)$. The annual population growth was $1.98 \%$ over the period 1995-2004 in the Philippines (WDI 2006). If we consider one period to be 20 years, then population growth in our model equals $g=1.481$. Furthermore we take the unskilled-to-skilled labor force $\left(\Theta=N^{l} / N^{h}\right)$ in 2000, which amounts to 3.5045, from Docquier and Marfouk (2006). ${ }^{17}$ This value is met by jointly fixing the education costs of a child belonging to high and low skilled parents: $x^{h}=0.19$ and $x^{l}=$ $0.04 .^{18}$ Finally, our aggregate data on remittances are taken from the International Monetary Fund (IMF 2007). Remittances amount to $\$ 7876$ million in 2003 and GDP PPP in 2003 corresponds to $\$ 326.6$ billion (WDI 2006). Thus the share of remittances to GDP equals to $2.41 \% .{ }^{19}$ From Docquier and Marfouk (2006), we know that 1.68 million migrants from the Philippines live in OECD countries of which $67.1 \%$ are high-skilled. For our central scenario we assume that skilled and unskilled remit

\footnotetext{
${ }^{15}$ See the recent World Bank report by Burgess and Haksar (2005) that stresses the importance of migration and remittances in the Philippines.

${ }^{16} \mathrm{At}$ the same time, the values for the education cost of a child belonging either to an unskilled individual, $x^{l}$, or to a skilled individual, $x^{h}$ have to satisfy condition (12).

${ }^{17}$ These authors compute the share of low to high skilled individuals from the Barro and Lee data (2001).

${ }^{18}$ One reason why $x$ may differ for children from skilled or unskilled parents is that the government may support education in low-income families. In several developing countries, conditional cash transfer programs have been adopted during the 1990s. Under these programs, low-income households receive a cash transfer if their children attend school. For a review on conditional cash transfer programs, see Das et al. (2005).

${ }^{19}$ According to the World Bank (2006), the remittance share of GDP in the Philippines would even amount to $13.5 \%$.(see World Bank, 2006, p.90, Figure 4.1).
} 
the same amounts than remittances from high-skilled as a share of GDP, $\Gamma$, which equals $1.62 \%$ and writes as follows: $\Gamma=\left(N^{h} M^{h}+N^{l} M^{l}\right) /\left(Y^{h}+Y^{l}\right)$. This assumption can be justified by the fact that high-skilled migrants are often employed as low-skilled workers at destination. We relax this assumption in section $4.4 .^{20}$ Finally the probability to emigrate is calibrated to $p=0.01088$, which - according to the numbers of high skilled workers in the Phillipine given by Docquier and Marfouk (2006) - corresponds to an emigration of about 77000 high skilled Philippine workers.

\subsection{Results}

We present here the effects of a more liberal immigration policy on household's behavior especially concerning fertility and education choices. An increase of $1 \%$ in the probability to emigrate amounts to 770 additional high skilled workers that emigrate. The effects of such a policy can be resumed as follows:

Proposition 2. The responses to the adoption of a more liberal immigration policy may differ for high and low skilled parents. But for the country as a whole, higher skilled emigration will in the long run, (i) reduce fertility levels and, (ii) enhance human capital formation.

Figure 1 shows how the choices of the households are influenced by the adoption of a laxer immigration policy (1\% increase in the chance to emigrate). At first sight, it seems surprising that in the short run high skilled parents prefer to raise more children and less educated ones, while low skilled parents behave in the opposite way. In fact, from the previous analysis in section 3.3, we should expect that both types of parents decide to finance higher education to a higher number of their children. However, since also general equilibrium effects are at play now, only low skilled parents increase the number of their high skilled children. In fact what differs between high skilled and low skilled parents' choice of high skilled children in equation (13) are the raising costs $\left(\phi w^{i}\right)$. Since wages decrease (see figure 3), it becomes relatively less expensive for skilled parents to raise more children and prefer thus to raise more children. This is formally expressed in (19). Since skilled parents choose to send less children to school, they can afford raising more children since their education expenditures $\left(x m^{i}\right)$ are reduced (last term in equation 19). This initial rise in the number of children and initial fall in educated children of skilled parents are due to the strong increase in the share of high to low skilled labor which drives the high skilled wage down. In the longer run,

\footnotetext{
${ }^{20}$ Actually, the fact that high and low skilled remit in the same way is not clear and is an on-going debate in the literature. Following Faini (2007) high skilled migrants have a smaller propensity to remit than low skilled migrants. We therefore relax our assumption in section 4.4 by considering a scenario in which the amount of remittances is lower, which implicitly means that high skilled individuals would have a lower propensity to remit.
} 
both variables ( $n^{h}$ and $m^{h}$ ) come back closer to their baseline level. The fertility/education choices of low skilled parents are more clear cut since they are mainly driven by the perspective of higher remittances.

Figure 1: Effects on household's decisions of a lax immigration policy ( $p$ increases by $1 \%$ )
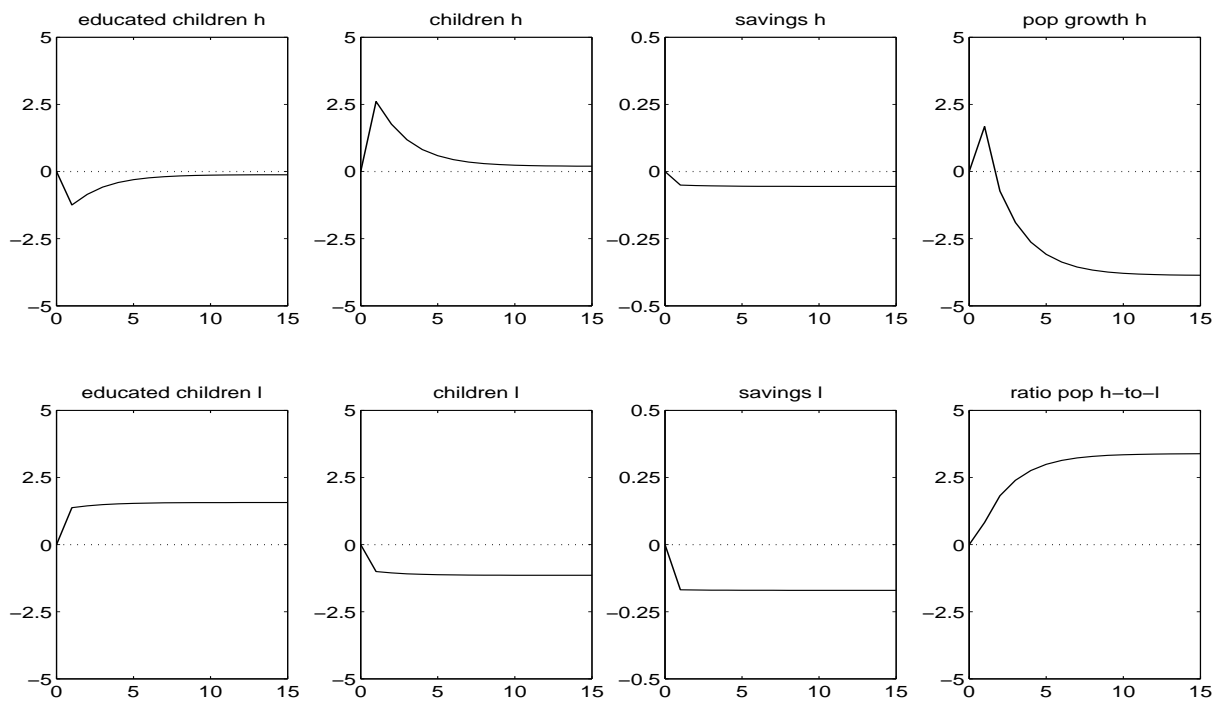

Values display percentage changes with respect to the baseline.

"l" refers to low and " $h$ " to high skilled individuals.

What about fertility? An increase in the probability to emigrate reduces the growth rate of population in the source country. We can infer the impact on total fertility from the last column of figure 1. It indicates the effects of a laxer immigration policy on the growth rate of the high skilled population (defined as the sum of adults and retired individuals) and on human capital (defined as the ratio of high-to-low skilled population). Since the growth of the skilled population declines but the share of skilled to unskilled population increases, total population declines. Actually, in the long run the population growth rate decreases by $3.87 \%$ with respect to the baseline due to a $1 \%$ increase in probability to emigrate. On the contrary, the share of high to low skilled population will increase by $3.39 \%$ in the long run. Thus increased skilled emigration leads to the standard quality-quantity trade-off, i.e., when parents choose more educated children they will raise less children (see e.g. Barro and Becker, 1988, de la Croix and Doepke, 2003). ${ }^{21}$ Thus increased skilled emigration reduces fertility and enhances human capital.

In the short run, the growth rate of the skilled population rises because the largest population group (low skilled) opts for more skilled children. This short term increase happens only for the skilled population (we do not show the one of the low skilled). In the long run, the growth rate

\footnotetext{
${ }^{21}$ Our static theoretical results show that this might not necessarily be the case.
} 
of the skilled and unskilled are the same and stabilize at a lower level compared to the baseline. This is because low skilled parents have less children, while high skilled keep to raise almost the same number of children than in the baseline. Thus total population is reduced (compared to the baseline). The ratio of high-to-low skilled population has changed and the average level of education of the remaining population is increased compared to the baseline ('ratio pop h-to-l'). In fact, not all additional educated individuals will be able to quit the country. In the terms coined by Beine et al. (2001), the "brain effect" (the investment in education) dominates the "drain effect" (the loss of skilled individuals). ${ }^{22}$ Clearly, the beneficial brain drain or "brain gain" is at play here.

We can also see from figure 1 that savings decrease for both types of parents. An income effect and a substitution effect are at play in equation (16). First, since wages decrease, both types of parents can save less. Also, since remittances increase due to higher emigration, adults need to save less for consumption when old. The fact that savings of low skilled decrease more than those of the skilled is due to the concavity of the utility function: one dollar of remittances has a higher marginal value for low than for high skilled.

Figure 2: Effects on economic indicators of a lax immigration policy ( $p$ increases by $1 \%$ )
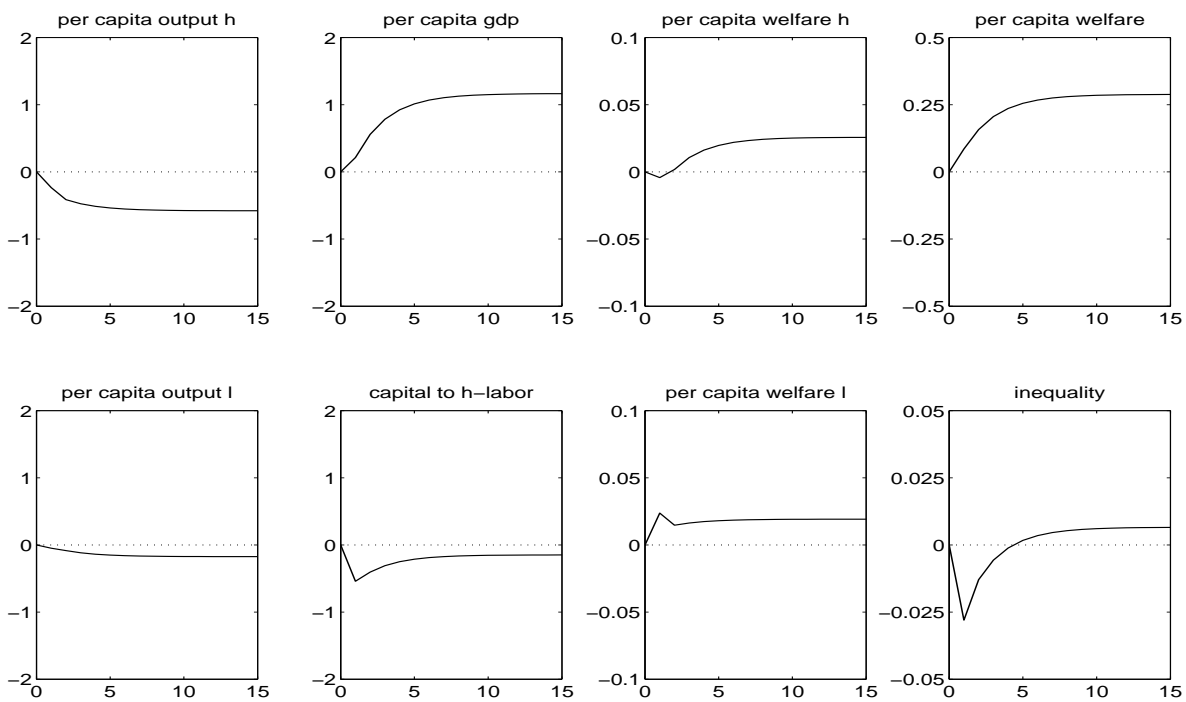

Values display percentage changes with respect to the baseline.

"l" refers to low and " $h$ " to high skilled individuals.

Figure 2 illustrates the effects of the laxer immigration policy on various economic indicators. In the first column we notice a slight drop in the ratios of sectoral outputs to corresponding populations, i. e. output in the high skilled (low skilled) sector to high skilled (low skilled) population. The reason is that since high skilled labor rises, capital per high skilled labor is reduced. (The strong first period

\footnotetext{
${ }^{22}$ The terms "brain effect" and "drain effect" were first used by Beine et al. but not the idea of a brain gain.
} 
decrease is due to the fact that the capital stock only slowly augments in the very short run). This induces a drop in per capita output of the high skilled as well in the wage of the high skilled. Thus the low skilled wage will fall as well ${ }^{23}$ and explains the fall in the per capita output of the low skilled. It seems at first sight paradoxical that the ratios of sectoral outputs to corresponding populations experience a reduction while (total) per capita GDP increases. The explanation is as follows. As the laxer immigration policy leads to an increase in the high skilled population compared to the low skilled population ("ratio pop h-to-l"), relatively more individuals will work in the more productive high skilled sector (where output per worker is higher).

The two last columns of figure 2 refer to changes in welfare. Changes in the welfare per skill group (column 3 ) is very small and slightly increasing (less than $0.025 \%$ ). However, since population shifts towards the skilled side, more people will enjoy the welfare level of a skilled individual. This explains why the welfare of the total population rises (around $0.25 \%$ ). Finally, wage inequality is decreased in the short run because low skilled individuals experience a higher welfare gain in the short run. But the long run effect on inequality is negligible $(<0.01 \%)$.

Figure 3: Effects of the laxer immigration policy on other variables
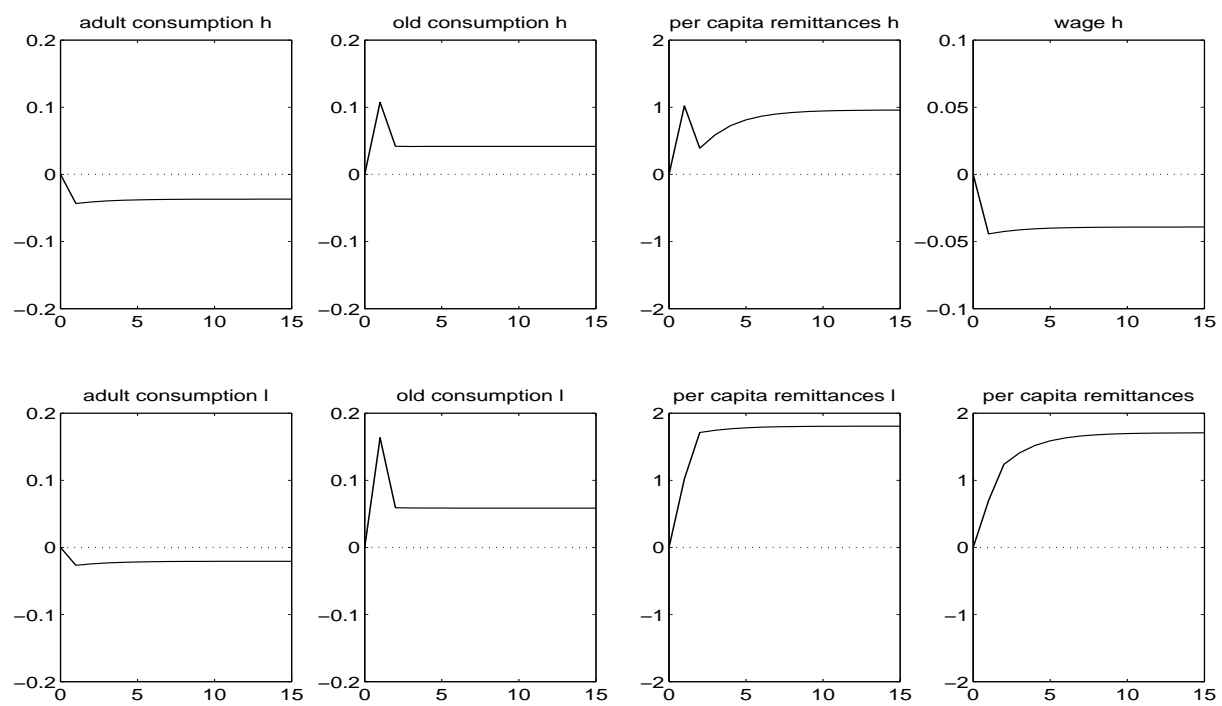

Values display percentage changes with respect to the baseline.

"l" refers to low and " $h$ " to high skilled individuals.

\footnotetext{
${ }^{23}$ Remember that wages in the low skilled sector are fixed with respect to wages in the skilled sector.
} 


\subsection{Robustness Analysis}

Proposition 3. The result, that a more liberal immigration policy will reduce overall fertility and enhance overall human capital levels in the long run, is robust under various different specifications of the model i.e. when the skill premium is variable and when high and low skilled parents differ in their time preference rates, altruism behaviors and propensities to remit.

In this section we provide different robustness checks for our results. For each of these alternative scenarios, we recalibrate the different exogenous variables used to meet the characteristics of the Philippine economy. First of all, we show that our results remain robust to an initial choice of $\mu .^{24}$ We show that for a choice of $\mu=0.25$ or $\mu=0.75$ instead of $\mu=0.50$, an increase in $p$ will still reduce fertility and enhance the level of human capital.

Apart from this more technical robustness check, we provide as well some more appealing variations to our model. First, we consider a variant in which the contribution of remittances to GDP, $\Gamma$, is only half as large as in the benchmark model, $\Gamma=0.81 \%$ instead of $1.62 \%$. Actually, the fact that high and low skilled remit in the same way is not clear and is an on-going debate in the literature. Following Faini (2006) high skilled migrants have a lower propensity to remit. ${ }^{25}$ Therefore our specification with a lower amount of remittances (denoted by LR) implicitly suggests that high skilled individuals have a smaller propensity to remit because they would contribute to a smaller share of the remittances observed (recall that remittances amount to 2.4\% of the GDP in the Philippines in 2003). The importance of time preference rates has received much attention in the literature, for example, the heterogeneity among countries, among individuals, or the endogenous formation of discount rates (see for example Becker and Mulligan, 1997). Here we want just to test the validity of our main results when high and low skilled individuals enjoy different discount rates: we denote this variant by 'heterogenous preferences' (HP). In this specification we assume that high skilled enjoy a higher discount factor $\beta^{h}=0.8$ than low skilled $\beta^{l}=0.6 .{ }^{26}$ Furthermore, we also take into account different altruism behaviors for high and low skilled individuals. We set a lower altruism factor for low skilled $\gamma^{l}=1.2512$, while for high skilled $\gamma^{h}=1.6675$ and refer to this specification as 'heterogenous altruism' (HA). Finally, in the two sector model developed by Galor and Zeira (1993), the skill premium $(\epsilon)$ is fixed. In a last model variant, labelled 'variable skill premium' (VSP), we allow $\epsilon$ to vary while the low skilled wage will be held constant.

Table 2 (in the appendix) compares the results under the benchmark specification with the results on different variants of the model. It shows the impacts on fertility, human capital, per capita GDP,

\footnotetext{
${ }^{24}$ Obviously provided $\mu$ does not take any extreme value (for instance 0 or 1 ).

${ }^{25}$ The reasons given by Faini are that high skilled migrants are likely to spend more time abroad and to reunite with their close family in the host country.

${ }^{26} \mathrm{~A} \beta^{l}=0.6$ suggests an annual discount rate of $2.59 \%$.
} 
per capita welfare, and (income-related) inequality when the probability to emigrate $p$ increases by $1 \%$. The magnitudes of the changes in the indicators across the specifications remain reasonable. For instance, the long run (period 20) elasticities to a $1 \%$ increase in $p$ vary between $-2.94 \%$ and $-5.33 \%$ for the population growth rate and between $2.77 \%$ and $4.57 \%$ for human capital. Table 3 scrutinizes the fertility and education decisions of the two types of households under the different specifications. We can observe that the long run (period 20) decisions on fertility and education are quite similar between the benchmark model and the variants VSP and $L R$, the results vary more under the specifications $H A$ and $H P$. This is even more true if we consider the fertility and education choices of high skilled households (sub-tables A and C) under the variants $H A$ and $H P$, since the low skilled individuals behave quite in the same way under the different variants.

When high skilled parents are more altruistic than low skilled $(H A)$, the differences in behaviors between high and low skilled are augmented. The reduction in the number of educated children $\left(m^{h}\right)$ and the increase in the number of total children $\left(n^{h}\right)$ are stronger in the long run than under the central variant ('benchmark'). On the contrary, when high and low skilled have different time preferences they behave more in the same way. We see that in the HP specification the long run choices of $m^{h}$ and $n^{h}$ are reversed compared to the benchmark and go in the same direction than the choices of low skilled. This explains why a $1 \%$ increase in the probability of emigration achieves the largest long run effects on total fertility and human capital formation under variant HP.

How to explain this long run reversal in the choices of the high skilled parents in the HP variant? Time preference factors affect savings behavior. Under the 'benchmark' model, skilled have a higher saving rate than unskilled. When low skilled have a lower preference rate (HP model), they save less and the difference in the saving rates between the two groups is even more marked. In the central variant ('benchmark'), the capital to high skilled labor ratio is decreased in the short run and comes back closer to its baseline value in the long run but remains below it. This is not anymore the case when time preferences of high and low skilled is (very) high. Under the HP variant, the capital to high skilled labor ratio first falls but will in the long run be slightly higher than its baseline value (more people belong to the high saving group). This implies that wages are less decreased in the long run under the HP variant than under the benchmark. Thus in the long run, it will not be anymore so interesting for skilled parents to raise more children and they can afford to pay education to larger number of their children. ${ }^{27}$

Nevertheless, our main results on fertility and education remain robust under both combination of preferences for high and low skilled and under all the different variants: total fertility is reduced, while human capital is enhanced in the long run.

\footnotetext{
${ }^{27}$ This reversal in the long run choices of skilled parents would not have happen if we would have chosen a much smaller gap in the time preferences.
} 


\section{Conclusion}

The present paper studies the effects of the brain drain and of remittances on the fertility and education decisions in the migrants' source country. Economists put more and more importance in fertility decisions since they affect human capital accumulation and thus economic outcomes. We develop an overlapping generations model with heterogenous agents who take fertility and education decisions for their children. Our main result is that a more liberal immigration policy at destination fosters human capital accumulation, by inducing parents to send more children to high school (high education). Their choice on the number children to raise is however ambiguous. Parents choose to raise more children if the perspective of receiving more remittances from their children dominates the increased education expenditures they have to face by sending more children to obtain higher education.

Finally, we also calibrate the model on the Philippine economy. We find that a $1 \%$ increase in the probability to emigrate leads to a long term decrease of $3.87 \%$ in the population growth rate, while the share of high to low skilled population will increase by $3.39 \%$.

A natural direction for further research involves the study of both low and high skilled migration and their joint impact on fertility and education decisions. In fact this would be an important extension of our research since low skilled migrants contribute greatly to the amount of remittances sent back to developing economies and since we showed the importance of remittances in fertility decisions. Furthermore it would also be worth investigating the role of migration determinants. This would involve to endogenize the migration and remittances decisions. Finally allowing for bequests would enrich the analysis on the impact of remittances on fertility decisions.

\section{References}

1. Adams R. (1998), Remittances, investment and rural asset accumulation in Pakistan, Economic Development and Cultural Change, 47(1), 155-173.

2. Adams R. (2005), Remittances, household expenditure and investment in Guatemala, Policy Research Working Paper Series, 3532, The World Bank.

3. Barro R.J. and Becker G. S. (1988), A reformulation of the economic theory of fertility, Quarterly Journal of Economics, 103(1), 1-25.

4. Barro R.J. and Lee L. (2001), International data on educational attainment: updates and implications, Oxford Economic Papers, 53(3), 541-563.

5. Becker G. S. and Mulligan C. B. (1997), The endogenous determination of time preference, 
The Quarterly Journal of Economics, MIT Press, vol. 112(3), 729-758.

6. Beine M., Docquier F. and Rapoport H. (2001), Brain drain and economic growth: theory and evidence, Journal of Development Economics, 64, 275-289.

7. Bhagwati J. and Hamada K. (1974), The brain drain, integration of markets for professionals and unemployment: A theoretical analysis, Journal of Development Economics, 1, 19-42

8. Böhning W.R. (1975), Some thoughts on emigration from the Mediterranean basin, International Labor Review, 111(3), 251-277.

9. Burgess R. and Haksar V. (2005), Migration and foreign remittances in the Philippines, IMF Working Paper 05/111.

10. Card D. (1990), The impact of the Mariel Boatlift on the Miami labor market, Industrial and Labor Relations Review, 43, 245-257.

11. Casarico A., Devillanove C., Stark O. and Uebelmesser S. (2008), International Migration, Human Capital Formation, and the Setting of Migration-Control Policies: Mapping the Gains, in J. Kornai, L. Mátyás and G. Roland eds., Corruption, Development and Institutional Design, Palgrave Macmillan, forthcoming.

12. Chami R., Fullenkamp C., and Jahjah S. (2005), Are immigrant remittance flows a source of capital for development, IMF Staff Papers 52(1), 55-81.

13. Chen H-J. (2006), International migration and economic growth: a source country perspective, Journal of Population Economics, 19, 725-748.

14. Das J., Do Q.T., and Ozler B. (2005), Reassessing conditional cash transfer programs, The World Bank Research Observer, 20(1), 57-80.

15. de la Croix D. and Doepke M. (2003), Inequality and growth: why differential fertility matters, American Economic Review, 93(4), 1091-1113.

16. de la Croix D. and Dottori D. (2008), Easter Island's collapse: a tale of a population race, Journal of Economic Growth, 13, 27-55.

17. Docquier F. (2006), Brain drain and inequality across nations, IZA Discussion Papers 2440, Institute for the Study of Labor (IZA).

18. Docquier F. and Marfouk A. (2006), Measuring international migration by educational attainment in 1990-2000, in C. Ozden and M. Schiff eds., International migration, remittances, and the brain-drain, Washington, D.C.: The World Bank. 
19. Docquier F. and Rapoport H. (2007), Skilled migration: The perspective of developing countries, IZA Discussion Papers 2873, Institute for the Study of Labor (IZA).

20. Dos Santos M. and Postel-Vinay F. (2003), Migration as a source of growth: the perspective of a developing country, Journal of Population Economics 16(1), 161-175.

21. Faini R. (2007), Remittances and the brain drain: Do more skilled migrants remit more? World Bank Economic Review 21(2), 177-191.

22. Friedberg R. M. and Hunt J. (1995), The impact of immigration on host country wages, employment and growth, Journal of Economic Perspectives, 9, 23-44.

23. Galor O. and Zeira J. (1993), Income distribution and macroeconomics, Review of Economic Studies, 60(1), 35-52.

24. Grubel H. and Scott A. (1966), The international flow of human capital, American Economic Review, 56, 268-274.

25. Haque N. and Kim S. (1995), Human capital flight: impact of migration on income and growth, IMF Staff Papers 42(3), 577-607.

26. Haveman R. and Wolfe B. (1995), The determinants of children's attainment: a review of methods and findings, Journal of Economic Literature, 33(4), 1829-1878

27. IMF (2007), International Monetary Fund, Balance of Payment Statistics (BOPS).

28. Lucas R. E. (1990), Why doesn't capital flow from rich to poor countries?, American Economic Review, 80(2), 92-96.

29. Lucas R. E. and Stark O. (1985) Motivations to remit: evidence from Botswana, Journal of Political Economy, University of Chicago Press, 93(5), 901-918.

30. McCormick B. and Wahba J. (2000), Overseas employment and Remittances to a Dual Economy, Economic Journal, Royal Economic Society, 110(463), 509-534.

31. Mountford A. (1997), Can a brain drain be good for growth in the source economy?, Journal of Development Economics, 53, 287-303.

32. Rapoport H. and Docquier F. (2005), The Economics of Migrants' Remittances, Handbook of the Economics of Giving, Altruism and Repciprocity, Vol 2, Edited by Serge-Christoph Kolm and Jean Mercier Ythier.

33. Rauch J. (2003), Diasporas and development: Theory, Evidence and Programmatic Implications, Department of Economics, University of California at San Diego. 
34. Rempel H. and Lobdell R. (1978), The role of urban-rural remittances in rural development, Journal of Development Studies, 14, 324-341.

35. Rosenzweig M. (2006), Global wage differences and international student flows, in Collins, Susan M. and Carol Graham, ed., Brookings Trade Forum, Global Labor Markets, 57-86.

36. Stark O. and Wang Y. (2002), Inducing human capital formation: migration as a substitute for subsidies, Journal of Public Economics, 86(1), 29-46.

37. Stark O., Helmenstein C. and Prskawetz A. (1997), A brain gain with a brain drain, Economics Letters, 55(2), 227-234.

38. Taylor E. (1999), The new economics of labour migration and the role of remittances in the migration process, International Migration, 1, 63-86.

39. UNESCO (2006), Data source for public school enrollment rate and public spending on education: Unesco, United Nations.

40. WDI (2006), World development indicators. Technical report, World Bank, ESDS International, University of Manchester.

41. World Bank (2006), Global Economic Prospects 2006: Economic Implications of Remittances and Migration, World Bank -Washington.

\section{A Appendix}

\section{A.1 Mathematical appendix of Section 3.3: Obtaining $s^{i}$ and $n^{i}$}

To obtain the response of $s$ to a change in $p$, we undertake the subsequent steps. First, combining (6) and (7) and rearranging the terms yields the following equation

$$
d_{t+1}^{i} \gamma w_{t+1}^{l}=\beta R_{t+1} \phi w_{t}^{i} E_{t}^{i}
$$

After replacing (1) and (4) into (35), we can rewrite the savings equation as

$$
\gamma w_{t+1}^{l} R_{t+1} s_{t}^{i}=\beta \phi w_{t}^{i} R_{t+1}\left[n_{t}^{i} w_{t+1}^{l}+m_{t}^{i}\left(\bar{w}_{t+1}-w_{t+1}^{l}\right)\right]-\gamma w_{t+1}^{l} M_{t+1}^{i} .
$$

From dividing the above equation on both sides by $w_{t+1}^{l} R_{t+1}$ and rearranging the terms, it follows

$$
s_{t}^{i}=\frac{\beta \phi}{\gamma} w_{t}^{i}\left[n_{t}^{i}+m_{t}^{i} \Delta_{t+1}\right]-\frac{M_{t+1}^{i}}{R_{t+1}},
$$


where $\Delta_{t+1}=\frac{\bar{w}_{t+1}}{w_{t+1}^{l}}-1$.

Furthermore, by plugging (3) and (4) into (6) yields

$$
R_{t+1} s_{t}^{i}+M_{t+1}^{i}=\beta R_{t+1}\left(w_{t}^{i}\left(1-\phi n_{t}^{i}\right)-s_{t}^{i}-x m_{t}^{i}\right),
$$

which gives

$$
\beta \phi w_{t}^{i} n_{t}^{i}=\beta\left(w_{t}^{i}-s_{t}^{i}-m_{t}^{i} x\right)-s_{t}^{i}-\frac{M_{t+1}^{i}}{R_{t+1}} .
$$

Combining (36) and (37), we have

$$
\begin{aligned}
s_{t}^{i} & =\frac{1}{\gamma}\left(\beta \phi w_{t}^{i} n_{t}^{i}+\beta \phi w_{t}^{i} m_{t}^{i} \Delta_{t+1}\right)-\frac{M_{t+1}^{i}}{R_{t+1}} \\
& =\frac{1}{\gamma}\left[\beta\left(w_{t}^{i}-s_{t}^{i}-x m_{t}^{i}\right)-s_{t}^{i}-\frac{M_{t+1}^{i}}{R_{t+1}}+\beta \phi w_{t}^{i} m_{t}^{i} \Delta_{t+1}\right]-\frac{M_{t+1}^{i}}{R_{t+1}} .
\end{aligned}
$$

Rearranging terms, we obtain the savings equation in the following form

$$
s_{t}^{i}=\frac{1}{1+\beta+\gamma}\left[\beta\left(w_{t}^{i}-m_{t}^{i} x+\phi w_{t}^{i} m_{t}^{i} \Delta_{t+1}\right)-(1+\gamma) \frac{M_{t+1}^{i}}{R_{t+1}}\right],
$$

which is equation (15).

Equation (11) can be rewritten as

$$
-x m_{t}^{i}+\phi w_{t}^{i} m_{t}^{i} \Delta_{t+1}=-\frac{\mu M_{t+1}^{i}}{R_{t+1}} .
$$

Substituting into the above saving equation, it follows

$$
s_{t}^{i}=\frac{1}{1+\beta+\gamma}\left[\beta w_{t}^{i}-(1+\gamma+\beta \mu) \frac{M_{t+1}^{i}}{R_{t+1}}\right] .
$$

Hence an increase in the probability to emigrate leads to

$$
\frac{\partial s_{t}^{i}}{\partial p}=-\frac{1+\gamma+\beta \mu}{1+\beta+\gamma} \frac{M_{t+1}^{i}}{R_{t+1}}\left[\frac{1}{p}+\frac{\mu}{m_{t}^{i}} \frac{\partial m_{t}^{i}}{\partial p}\right]<0,
$$

which is equation (17).

Finally to obtain the change in $n$ following a change in $p$, we proceed in the following way. In (35), using the definitions (1), (4), and (11), and rearranging the terms yields

$$
\phi \beta w_{t}^{i} n_{t}^{i}=\gamma s_{t}^{i}-\beta x m_{t}^{i}+(\gamma+\beta \mu) \frac{M_{t+1}^{i}}{R_{t+1}} .
$$

Combining (16) and (41), it follows

$$
\phi \beta w_{t}^{i} n_{t}^{i}+\beta x m_{t}^{i}=\frac{\gamma \beta w_{t}^{i}}{1+\beta+\gamma}+\frac{(\gamma+\mu+\mu \beta) M_{t+1}^{i}}{(1+\beta+\gamma) R_{t+1}},
$$

which gives (18).

A change in $p$ yields

$$
\phi \beta w_{t}^{i} \frac{\partial n_{t}^{i}}{\partial p}=\frac{(\gamma+\mu+\beta \mu)}{(1+\beta+\gamma)} \frac{M_{t+1}^{i}}{R_{t+1}}\left[\frac{1}{p}+\frac{\mu}{m_{t}^{i}} \frac{\partial m_{t}^{i}}{\partial p}\right]-\beta x \frac{\partial m_{t}^{i}}{\partial p},
$$

which is showed in (19). 


\section{A.2 Additional scenarios}

In the subsequent figures we do some robustness checks of our simulations. The effects on the source country of an even more liberal immigration policy (10\% increase in the probability to emigrate), of more restrictive immigration policy (decrease of $1 \%$ in the probability to emigrate), of a more liberal immigration policy when $\mu=0.25$, when $\mu=0.75$ and are respectively shown in figure 4 , figure 5 , figure 6 and figure 7. The impact of an increase in $p$ by $1 \%$ under different variants of the model is depicted in table 2. 
Figure 4: Effects of a $10 \%$ increase in the $p$
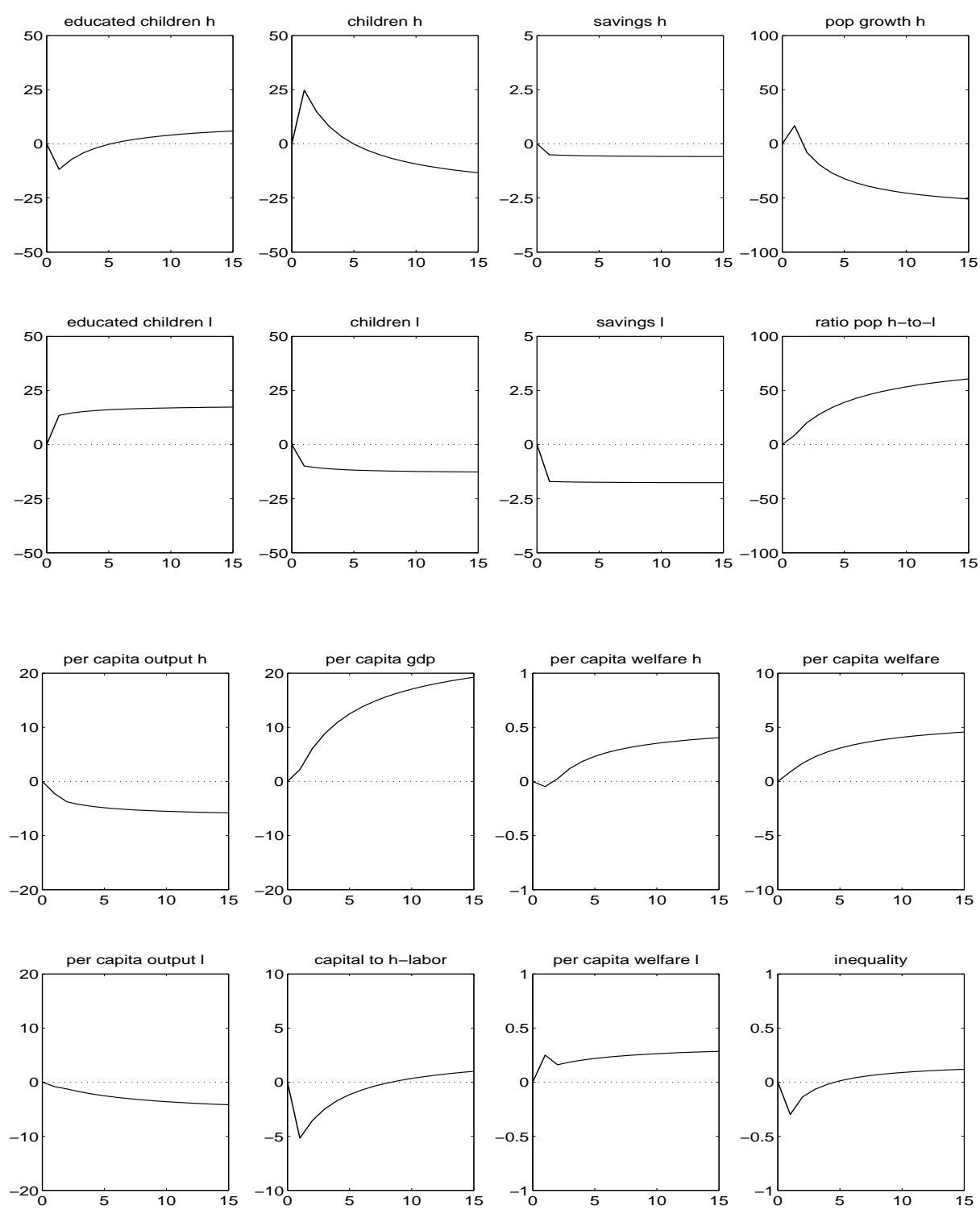

Values display percentage changes with respect to the baseline.

"l" refers to low and " $h$ " to high skilled individuals. 
Figure 5: Effects of a stricter immigration policy ( $p$ decreases by $1 \%$ )
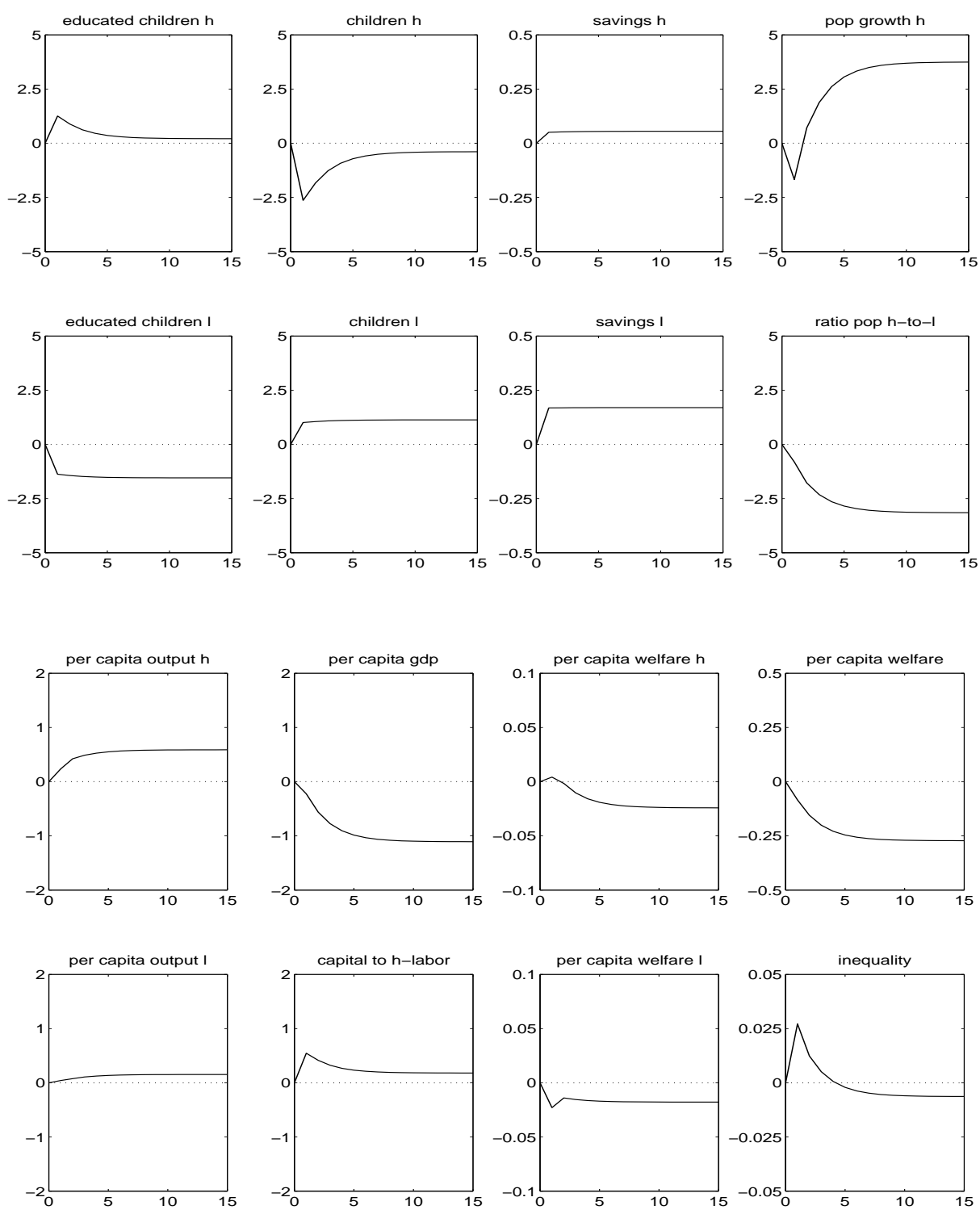

Values display percentage changes with respect to the baseline.

"l" refers to low and " $h$ " to high skilled individuals. 
Figure 6: Effects of a more liberal immigration policy when $\mu=0.25$ ( $p$ increases by $1 \%$ )
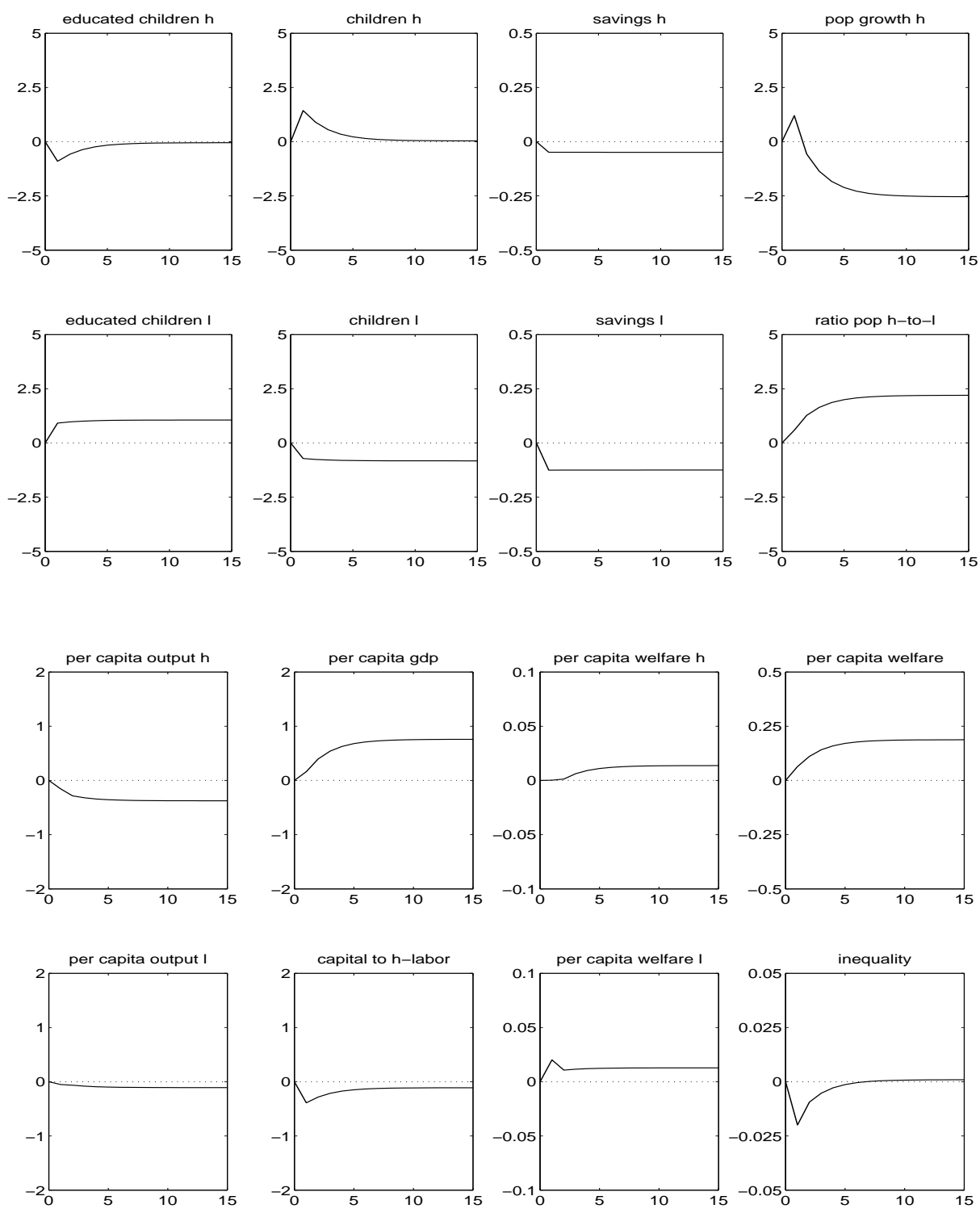

Values display percentage changes with respect to the baseline.

"l" refers to low and "h" to high skilled individuals. 
Figure 7: Effects of a more liberal immigration policy when $\mu=0.75$ ( $p$ increases by $1 \%$ )
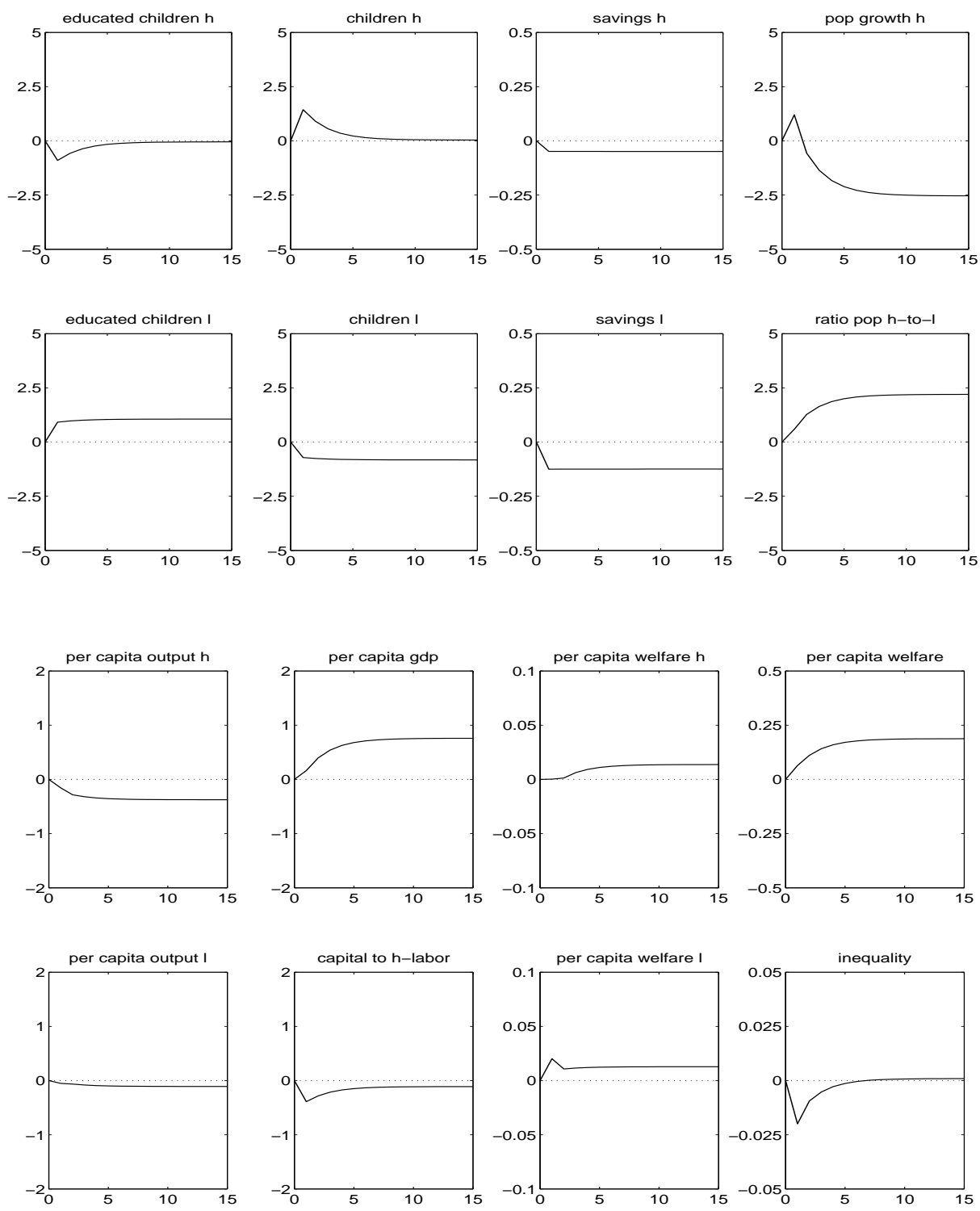

Values display percentage changes with respect to the baseline.

"l" refers to low and "h" to high skilled individuals. 
Table 2: Effect on main indicators of a $1 \%$ increase in $p$ under different model specifications

\begin{tabular}{|c|c|c|c|c|c|c|c|}
\hline Period & 1 & 2 & 3 & 5 & 10 & 15 & 20 \\
\hline \multicolumn{8}{|c|}{ A. Population growth rate } \\
\hline Benchmark & -0.96 & -2.11 & -2.76 & -3.42 & -3.82 & -3.86 & -3.87 \\
\hline Heterogenous Altruism (HA) & -0.95 & -1.94 & -2.39 & -2.77 & -2.93 & -2.94 & -2.94 \\
\hline Heterogenous Preferences (HP) & -0.96 & -2.22 & -3.08 & -4.13 & -5.08 & -5.29 & -5.33 \\
\hline Variable skill premium (VSP) & -1.00 & -2.20 & -2.86 & -3.50 & -3.84 & -3.87 & -3.87 \\
\hline Lower Amount of Remittances & -0.97 & -2.15 & -2.83 & -3.51 & -3.91 & -3.95 & -3.96 \\
\hline \multicolumn{8}{|c|}{ B. Human capital } \\
\hline Benchmark & 0.82 & 1.82 & 2.40 & 2.99 & 3.35 & 3.38 & 3.39 \\
\hline HA & 0.81 & 1.74 & 2.20 & 2.59 & 2.76 & 2.77 & 2.77 \\
\hline HP & 0.82 & 1.90 & 2.62 & 3.53 & 4.35 & 4.53 & 4.57 \\
\hline VSP & 0.86 & 1.91 & 2.49 & 3.06 & 3.36 & 3.38 & 3.39 \\
\hline LR & 0.82 & 1.84 & 2.44 & 3.05 & 3.41 & 3.45 & 3.45 \\
\hline \multicolumn{8}{|c|}{ C. Per capita GDP } \\
\hline Benchmark & 0.21 & 0.56 & 0.78 & 1.01 & 1.15 & 1.17 & 1.17 \\
\hline HA & 0.21 & 0.50 & 0.66 & 0.81 & 0.87 & 0.87 & 0.87 \\
\hline HP & 0.22 & 0.63 & 0.94 & 1.32 & 1.67 & 1.74 & 1.75 \\
\hline VSP & 0.22 & 0.59 & 0.82 & 1.04 & 1.16 & 1.17 & 1.17 \\
\hline LR & 0.22 & 0.58 & 0.81 & 1.05 & 1.19 & 1.20 & 1.20 \\
\hline \multicolumn{8}{|c|}{ D. Per capita welfare } \\
\hline Benchmark & 0.09 & 0.16 & 0.21 & 0.26 & 0.29 & 0.29 & 0.29 \\
\hline HA & 0.08 & 0.14 & 0.18 & 0.21 & 0.22 & 0.22 & 0.22 \\
\hline HP & 0.08 & 0.16 & 0.22 & 0.29 & 0.36 & 0.37 & 0.38 \\
\hline VSP & 0.09 & 0.17 & 0.21 & 0.26 & 0.29 & 0.29 & 0.29 \\
\hline LR & 0.08 & 0.16 & 0.21 & 0.26 & 0.29 & 0.29 & 0.29 \\
\hline \multicolumn{8}{|c|}{ E. Inequality } \\
\hline Benchmark & -0.028 & -0.013 & -0.006 & 0.002 & 0.006 & 0.007 & 0.007 \\
\hline HA & -0.030 & -0.012 & -0.005 & 0.001 & 0.004 & 0.004 & 0.004 \\
\hline HP & -0.020 & 0.002 & 0.015 & 0.031 & 0.045 & 0.048 & 0.048 \\
\hline VSP & -0.030 & -0.014 & -0.006 & 0.002 & 0.006 & 0.006 & 0.006 \\
\hline LR & -0.023 & -0.010 & -0.003 & 0.003 & 0.008 & 0.008 & 0.008 \\
\hline
\end{tabular}

The table displays percentage changes with respect to the baseline. 'Benchmark' refers to our benchmark model as defined in sections 4.2 and 3. In the 'HA' specification skilled individuals have an altruism parameter $\gamma^{h}=1.6675$ and low skilled individuals $\gamma^{l}=1.2512$. The preference factor of high skilled indivduals equals $\beta^{h}=0.8$ and for low skilled $\beta^{l}=0.6$ ('HP' model). In the 'VSP' model the skill premium $\left(w_{0}^{h} / w_{0}^{l}\right)$ is allowed to vary. In the model 'LR' the amount of remittances is lower. 
Table 3: Effect on households' fertility decisions of a change in $p$ (under different variants)

A. High skilled children of high skilled parents $\left(m^{h}\right)$

\begin{tabular}{lccccccc}
\hline Period & 1 & 2 & 3 & 5 & 10 & 15 & 20 \\
\hline Benchmark & -1.24 & -0.85 & -0.58 & -0.30 & -0.14 & -0.12 & -0.12 \\
Heterogenous Altruism (HA) & -1.06 & -0.84 & -0.69 & -0.56 & -0.51 & -0.50 & -0.50 \\
Heterogenous Preferences (HP) & -1.33 & -0.78 & -0.37 & 0.15 & 0.61 & 0.71 & 0.73 \\
Variable skill premium (VSP) & -1.34 & -0.91 & -0.57 & -0.28 & -0.13 & -0.12 & -0.12 \\
Lower Amount of Remittances (LR) & -1.28 & -0.85 & -0.57 & -0.29 & -0.13 & -0.11 & -0.11 \\
\hline \hline
\end{tabular}

B. High skilled children of low skilled parents $\left(\mathrm{m}^{l}\right)$

\begin{tabular}{lccccccc}
\hline Period & 1 & 2 & 3 & 5 & 10 & 15 & 20 \\
\hline Benchmark & 1.37 & 1.44 & 1.49 & 1.54 & 1.56 & 1.57 & 1.57 \\
HA & 1.46 & 1.49 & 1.51 & 1.53 & 1.54 & 1.54 & 1.54 \\
HP & 1.34 & 1.44 & 1.51 & 1.60 & 1.68 & 1.70 & 1.70 \\
VSP & 1.45 & 1.52 & 1.52 & 1.55 & 1.57 & 1.57 & 1.57 \\
LR & 1.39 & 1.46 & 1.50 & 1.55 & 1.58 & 1.58 & 1.58 \\
\hline \hline
\end{tabular}

C. Total children of high skilled parents $\left(n^{h}\right)$

\begin{tabular}{lccccccc}
\hline Period & 1 & 2 & 3 & 5 & 10 & 15 & 20 \\
\hline Benchmark & 2.61 & 1.76 & 1.18 & 0.59 & 0.23 & 0.20 & 0.19 \\
HA & 2.37 & 1.86 & 1.52 & 1.22 & 1.10 & 1.09 & 1.09 \\
HP & 2.70 & 1.57 & 0.71 & -0.36 & -1.32 & -1.52 & -1.57 \\
VSP & 2.81 & 1.89 & 1.17 & 0.55 & 0.23 & 0.20 & 0.19 \\
LR & 2.69 & 1.77 & 1.17 & 0.56 & 0.21 & 0.17 & 0.17 \\
\hline \hline
\end{tabular}

D. Total children of low skilled parents $\left(n^{l}\right)$

\begin{tabular}{lccccccc}
\hline Period & 1 & 2 & 3 & 5 & 10 & 15 & 20 \\
\hline Benchmark & -1.05 & -1.09 & -1.11 & -1.13 & -1.14 & -1.15 & -1.15 \\
HA & -1.03 & -1.04 & -1.05 & -1.06 & -1.06 & -1.06 & -1.06 \\
HP & -1.08 & -1.13 & -1.17 & -1.22 & -1.26 & -1.27 & -1.28 \\
VSP & -1.11 & -1.11 & -1.13 & -1.14 & -1.14 & -1.15 & -1.15 \\
LR & -1.08 & -1.11 & -1.13 & -1.16 & -1.17 & -1.17 & -1.17 \\
\hline \hline
\end{tabular}

The table displays percentage changes with respect to the baseline. 'Benchmark' refers to our benchmark model as defined in sections 4.2 and 3. In the 'HA' specification skilled individuals have an altruism parameter $\gamma^{h}=1.6675$ and low skilled individuals $\gamma^{l}=1.2512$. The preference factor of high skilled indivduals equals $\beta^{h}=0.8$ and for low skilled $\beta^{l}=0.6$ ('HP' model). In the 'VSP' model, the skill premium $\left(w_{0}^{h} / w_{0}^{l}\right)$ is allowed to vary. In the model 'LR', the amount of remittances is lower. 